\title{
ESTÁ CHOVENDO NO MOLHADO? A VISÃO ACADÊMICA SOBRE O DESENVOLVIMENTO SUSTENTÁVEL EM UM CONTEXTO DE CRISE
}

\author{
IT'S RAINING IN THE WET? THE ACADEMIC VIEW \\ ON SUSTAINABLE DEVELOPMENT \\ IN A CRISIS CONTEXT
}

\author{
Recebido 21-11-2013 \\ Aceito 20-04-2014 \\ Minelle Enéas da Silva ${ }^{1}$ \\ Ana Paula Ferreira Alves ${ }^{2}$ \\ Gabriele Volkmer ${ }^{3}$
}

\section{RESUMO}

Uma das crises mais recentes do capitalismo, entre 2007 e 2008, ainda deixa rastros marcantes nas economias de diversos países. Nesse contexto, o conceito de desenvolvimento sustentável desponta como alternativa que busca vincular a dinâmica econômica às variações que podem estar relacionadas com perspectivas sociais e preocupações ambientais. Entretanto, apesar de bastante difundidas, as definições de desenvolvimento sustentável podem ser consideradas vagas e ambíguas. Assim, este estudo objetiva identificar como a temática do desenvolvimento sustentável vem sendo abordada em meio ao contexto atual de crise do capitalismo. Para tanto, utiliza-se de uma perspectiva crítica sobre o que foi publicado acerca da temática no evento Encontro Nacional de Gestão Empresarial e Meio Ambiente (ENGEMA) entre 2008 e 2012. Como resultados, no contexto acadêmico brasileiro, identificou-se uma tendência à adequação das questões socioambientais para a manutenção do capitalismo, com a utilização muitas vezes equivocada da temática estudada. No entanto, em alguns casos, pesquisas conseguem discutir a temática de forma mais profunda e realizam questionamentos acerca do tema sob uma perspectiva mais voltada à mudança.

Palavras-chave: Crise do capitalismo, desenvolvimento sustentável, produção acadêmica.

\footnotetext{
${ }^{1}$ Possui graduação em Administração pela Universidade Federal de Campina Grande - UFCG, mestrado em Administração pela Universidade Federal de Pernambuco - UFPE. Atualmente é doutorando em Administração pela Universidade Federal do Rio Grande do Sul - UFRGS. Porto Alegre, Rio Grande do Sul, Brasil. E-mail: minele.adm@gmail.com

${ }^{2}$ Possui graduação em Administração e em Ciências Contábeis pela Universidade Federal do Rio Grande - FURG. Possui mestrado em Administração pela Universidade Federal do Rio Grande do Sul - UFRGS.

${ }^{3}$ Possui graduação em Ciências Biológicas pela Universidade Federal do Rio Grande do Sul - UFRGS. Atualmente é mestranda em Administração pela Universidade Federal do Rio Grande do Sul - UFRGS. Porto Alegre, Rio Grande do Sul, Brasil. E-mail: gabrielevolkmer@ gmail.com
} 


\section{ABSTRACT}

One of the latest crises of capitalism, between 2007 and 2008, still leaves marked trails in the economies of many countries. In this context, the concept of sustainable development has emerged as an alternative that seeks to link economic dynamics variations that may be related to social perspectives and environmental concerns. However, although quite widespread, definitions of sustainable development can be considered vague and ambiguous. The objective of this paper is to identify how the issue of sustainable development has been approached amid the current context of the capitalism crisis. To do so, it approached a critical perspective on what has been published on the subject at the event Encontro Nacional de Gestão Empresarial e Meio Ambiente (ENGEMA), between 2008 and 2012. As a result, in the Brazilian academic context, we identified a trend toward adequacy of social-environmental issues for the maintenance of capitalism, approaching the theme studied often mistaken. However, in some cases, research was able to discuss the subject more deeply and conduct inquiries on the subject from a perspective more focused on change.

Keywords: Crisis of Capitalism, sustainable development, academic production.

\section{INTRODUÇÃO}

O capitalismo trouxe consigo um sistema de produção que vem agravando a degradação do planeta, desencadeando um comportamento social caracterizado por desperdício e consumismo exagerado de recursos. Os problemas decorrentes desse sistema evidenciam que esse modo de produção é socialmente injusto, ambientalmente desequilibrado e economicamente inviável para aqueles que não têm os requisitos para se adequar às suas precondições (ELKINGTON, 2001), indicando que o sistema, como um todo, passa por crises inevitáveis. Uma de suas crises mais recentes, entre 2007 e 2008, ainda deixa seus rastros pelas economias de diversos países, impactando a dinâmica econômica, a política, o mercado de cada região. Dessa forma, é possível perceber que o sistema deve passar - e está passando - por mudanças.

A influência do capitalismo não está somente no modo como se produz, mas também no modo de consumir, uma vez que, atualmente, consumir mais é sinônimo de bem-estar e felicidade. Um sistema mundial que predomina a riqueza de uns em virtude da pobreza de todos os outros, onde poucos têm muito e muitos têm pouco, traz consigo a necessidade latente de mudança. Entretanto, não é provável que aconteça mudanças no padrão de consumo e no estilo de vida atual se não ocorrer uma mudança de valores e comportamentos - uma sublimação do valor "ter mais" para o valor "ter melhor". É necessário que a noção de felicidade se desloque do consumir para o usufruir (NASCIMENTO, 2012).

O deslocamento do crescimento econômico para uma qualidade de vida, nos países desenvolvidos, reforça a ideia de que é possível viver melhor reduzindo e consumindo menos (VEIGA, 2010). Nesse contexto, o conceito de desenvolvimento sustentável desponta como uma alternativa que busca vincular a dinâmica econômica às variações que podem estar relacionadas com perspectivas sociais e preocupações ambientais. Sua base está na discussão sobre mudanças em diferentes contextos, o que sugere a necessidade de visão pragmática e preocupação discursiva. Essas questões têm se tornado cada vez mais relevantes, levando governantes, sociedades civis e organizações a proporem diferentes medidas para a preservação dos recursos naturais e para a melhoria da qualidade de vida das pessoas.

É notável que cidadãos, profissionais, empresários e pesquisadores acadêmicos têm adotado comportamentos mais críticos em relação à sustentabilidade, dando início a um processo de conscientização sobre a importância da preservação ambiental e envidando esforços com pesquisas e estudos a fim de encontrar alternativas para o uso correto e sustentável dos recursos naturais. 
Entretanto, apesar de bastante difundidas, as definições de desenvolvimento sustentável podem ser consideradas vagas e ambíguas, predominando, na realidade, a falta de consenso sobre o seu significado (CLARO; CLARO; AMÂNCIO, 2008). Essa ideia, de acordo com Fergus e Rowney (2005), exige discussões mais profundas sobre sua viabilidade e sobre a mudança potencial no meio.

Diante dessas considerações, o objetivo desse estudo é identificar como a temática do desenvolvimento sustentável vem sendo abordada em meio ao contexto atual de crise do capitalismo, através análise dos Anais de quatro anos (de 2008 a 2012) do evento Encontro Nacional de Gestão Empresarial e Meio Ambiente (ENGEMA), considerando que o período é sequencial à efetivação da atual crise do sistema capitalista, iniciada entre os anos 2007 e 2008. Para tanto, utiliza-se de uma perspectiva crítica sobre o que vem sendo publicado acerca dessa temática. Justifica-se a realização da presente pesquisa uma vez que: (a) a crise pode interferir diretamente nas discussões quanto ao desenvolvimento sustentável; e (b) o evento é voltado a pesquisadores da temática, refletindo, portanto, o pensamento destes no momento de crise.

Assim sendo, como forma de melhor compreender a proposta do artigo, este está dividido em quatro seções, além desta parte introdutória. Em um primeiro momento, discute-se sobre a crise do capitalismo, o emergir do desenvolvimento sustentável e a adequação dos debates já realizados. Em seguida, apresentam-se os procedimentos metodológicos que nortearam o desenvolvimento desta pesquisa. Posteriormente, apresentam-se, na seção seguinte, os dados que foram levantados e as análises para atendimento dos objetivos propostos, bem como as implicações acadêmicas das discussões realizadas. E, por fim, identificam-se as considerações finais que servem para indicar as reflexões realizadas, bem como destacar as contribuições que emergem desta pesquisa.

\section{DISCUSSÃO TEÓRICA}

\subsection{Em tempos de crise, o capitalismo sobrevive?}

O capitalismo está enfrentando uma crise econômica, principalmente relacionada à incapacidade de vender o que é produzido e criar lucros - fato que indica que o sistema pode não se sustentar ao longo do tempo (ONARAN, 2010; VANDEPITTE, 2011). Seguindo essa ideia, Foster e Magdoff (2011) consideram que existe apenas uma solução possível para essa crise planetária: a chamada eutanásia do capitalismo. Para os autores, tal eutanásia ocorre por meio da substituição do velho sistema por uma nova economia, orientada para um desenvolvimento mais sustentável, uma plenitude ecológica e um cultivo autêntico da comunidade humana. Nessa perspectiva, ao considerar que a crise existe e que uma alternativa é possível, o que falta para o desenvolvimento sustentável?

Karl Marx, em sua crítica ao capitalismo, argumentou que a consolidação desse sistema se deu por meio de uma revolução - no caso, a industrial. No entanto, por meio da produção de consciência individual, esse autor indica a possibilidade do emergir de uma nova visão. Marx pensou o capitalismo como aquele que desenvolveu as forças de produção até certo ponto, sob diferentes relações sociais, e que seria possível a emancipação dos indivíduos no contexto da sociedade (EAGLETON, 2011). Portanto, o reconhecimento social, por meio de uma nova consciência, se classificaria como alternativa para a situação de crise, que implica uma necessidade de mudança no modo de produção, necessidade essa que pode ser o ponto inicial para uma revolução.

Apesar do grande entendimento acerca das condições de crise do sistema de produção adotado, tanto as grandes corporações quanto o próprio setor financeiro vêm tentando esca- 
par ao máximo do reconhecimento de um colapso do capitalismo (DE COCK; BAKER; VOLKMAN, 2011). Entretanto, sempre que capitalistas falarem sobre o capitalismo, sabe-se que o sistema está em apuros (EAGLETON, 2011). Essa decadência não seria algo totalmente inesperado, visto que revoluções nos modos de produção ocorrem "periodicamente", isto é, nenhum sistema de produção até então conseguiu perdurar indefinidamente ao longo do tempo (MANDEL, 2001). Tal fato pode ser observado em Eagleton (1997), que aponta que o capitalismo superestimou sua produção, preparando o caminho para sua própria negação.

Ao longo de sua existência como preponderante modo de produção, o capitalismo vem apresentando variações (crises) que fazem parte de um sistema de produção e que, muitas vezes, o fortalecem. Todavia, desde o segundo semestre de 2007, a economia capitalista passou a enfrentar uma grave crise sistêmica, comparável à Grande Depressão. Embora a crise tenha sido originada nos Estados Unidos, seu impacto vem se refletindo em diversos países, principalmente na Europa, com grande destaque ao caso da Grécia (ONARAN, 2010). Isso evidencia a amplitude que o contexto capitalista tem sobre a sociedade e que as taxas de crescimento econômico dos países no centro do capitalismo se deslocam em baixa velocidade (FOSTER; MAGDOFF, 2011).

O mercado mundial (bens de consumo, serviços e finanças) subordinou-se, manipulou e estruturou-se em favor dos principais países capitalistas (VANDEPITTE, 2011). No entanto, como percebem Foster e Magdoff (2011), as economias capitalistas avançadas são capturadas em uma tendência à estagnação resultante dos processos de maturação industrial e acumulação monopolista. Nessa perspectiva, a diferença entre comuns ciclos econômicos que ocorrem na periferia mundial e essa crise atual é que esta tem impacto global, além de ter se originado em países capitalistas centrais (ONARAN, 2010). Portanto, essa crise tem assumido um caráter mais impactante sobre todo o contexto mundial, o que diferencia a forma de se olhar para esse cenário.

Como alternativa ao processo de crise, alinhada à perspectiva de mudança e reestruturação do sistema de produção, emergem as discussões sobre o desenvolvimento sustentável. Sua ideia básica relaciona-se com mudanças na atuação de diferentes atores da sociedade voltados para a busca por uma harmonização entre os aspectos sociais, econômicos e ambientais (WCDE, 1987). O desenvolvimento sustentável apresenta-se como possível à medida que as características individualistas estimuladas pelo capitalismo forem direcionadas para uma visão mais coletiva (FOLADORI, 2005). Apesar de um debate mais focado na coletividade e na busca por equilíbrio e equidade na utilização dos recursos existentes, muito ainda é discutido acerca da possibilidade de adequação dessa ideia ao pensamento capitalista.

Para Prothero e Fitchett (2000, p. 48), "qualquer definição que usa entendimentos contemporâneos da natureza e das necessidades humanas para definir a sociedade verde não pode ser considerada distinta do modo de produção capitalista, uma vez que esses termos emergiram como parte das condições culturais do capitalismo". Porém, para acadêmicos que discutem desenvolvimento sustentável como essência de mudanças nos valores sociais, essa afirmação se apresenta como insulto a toda discussão até então criada. A verdadeira essência do desenvolvimento sustentável não é trazer um novo perfil ao declínio capitalista com a mercantilização (SMITH, 2007), mas buscar o emergir de nova visão que, de certo modo, pode ser conquistada a partir do surgimento de uma maior consciência socioambiental.

Mesmo com esse pensamento, tem-se realizado ações contra os preceitos básicos dessa nova forma de se ver o sistema produtivo - como é o caso do mercado de carbono. Muitos ainda veem os mercados de carbono como uma ferramenta viável para lidar com as mudanças climáticas, não por meio de uma mudança de visão, mas considerando-o como uma forma de reinventar o capitalismo, com base em práticas de "esverdeamento" do que vem sendo até então 
praticado. Existem evidências que mostram que as recentes práticas "verdes" financiadas por esses mercados de carbono (ditas projetadas no sentido do desenvolvimento sustentável) podem ser consideradas como patologia capitalista (BÖHM; MIZOCSKY; MOOG, 2012). Continua-se, assim, com a determinação de novas áreas para o capitalismo (SMITH, 2007).

Ao contrário do que aponta Onaran (2010) sobre o desenvolvimento sustentável - de que visa à necessidade de crescimento zero ou baixo para as economias de países desenvolvidos -, o que esse desenvolvimento realmente prevê é a necessidade de reestruturação nos modos de produção e nas relações de consumo, para que possa haver melhor articulação na sociedade. Esse conceito é apresentado por Hopwood, Mellor e O’Brien (2005), no momento em que os autores indicam diferentes abordagens para o desenvolvimento sustentável, a partir de um sentido transitório, no qual não se deve manter o status quo, como muitos pregam (o caso do "esverdeamento" do capitalismo), mas sim buscar uma transformação maior, com a utilização de novas lentes e nova consciência.

É nesse sentido que se trabalha a visão de uma longa transição na sociedade para uma nova perspectiva (ONARAN, 2010), argumentando-se que a produção de consciência surge como o ponto inicial para esse processo de mudança. Essa produção está alinhada ao que Marx (1980) indicou sobre a necessidade de envolvimento dos indivíduos por meio de suas relações sociais, estimulando um pensamento alternativo, não voltado para um contexto de socialismo ou comunismo, mas que pudesse ser utilizado para uma mudança focada no desenvolvimento sustentável.

\subsection{Desenvolvimento sustentável: um novo modelo}

As transformações que vêm sendo observadas em diferentes âmbitos no mundo são resultantes das práticas produtivas e do alto consumo da população e estão gerando redução na capacidade de carga do planeta, bem como grandes impactos sobre os recursos naturais. Para melhor atuação do ser humano no meio, novas perspectivas socioeconômicas, tecnológicas, políticas e ambientais devem estar em consonância com as discussões que vêm sendo desenvolvidas para melhorar a qualidade de vida da sociedade (BUARQUE, 2008). Dessa maneira, são incentivadas a conservação e a melhora das bases de recursos naturais, a reorientação da tecnologia e a fusão de ambiente e economia em um processo de decisão voltada a um equilíbrio entre os benefícios coletivos (WCDE, 1987).

Essas mudanças observadas mostram que a atual prática de desenvolvimento visa à evidenciação do capital econômico em relação aos capitais social e natural (HAWKEN; LOVINS; LOVINS, 1999). Tal fato ocorre tendo em vista a miopia sobre a abundância de recursos. Nesse sentido, torna-se visível que o maior desafio, atualmente, é transformar o crescimento econômico capitalista em um modelo de desenvolvimento sustentável (DS) (BROWN, 2003; CANEPA, 2007), no qual as atitudes individualistas devem ser modificadas e direcionadas para questões coletivas com as mudanças nos valores humanos (NORTON, 2007). Todavia, apesar dessas considerações, Elkington (2001) indica que o capitalismo e a sustentabilidade não compõem uma fácil aliança, o que sugere a necessidade de novos elementos para esse paradigma emergente.

A mudança no modelo de desenvolvimento consegue designar, ao mesmo tempo, o surgimento de subsídios para a sobrevivência humana no meio e um novo enfoque de planejamento e gestão, no qual as práticas atuais redirecionem suas ações para questões mais amplas e coletivas, demonstrando um diferente papel a ser praticado pelos atores envolvidos (SACHS, 2008). A referida mudança sugere uma nova visão de todos os stakeholders, no sentido de alteração das práticas adotadas, a fim de que haja compreensão, incorporação e atitudes mais amplas como 
condição essencial para que os indivíduos entendam e percebam os resultados positivos dessas transformações (BUARQUE, 2008; CANEPA, 2007).

Nesse novo contexto, o conceito mais difundido para desenvolvimento sustentável foi o definido no Relatório de Brundtland, compreendido como "um processo de mudança em que a exploração dos recursos, a direção dos investimentos, a orientação do desenvolvimento tecnológico e a mudança institucional estão todos em harmonia" para que as necessidades humanas possam ser satisfeitas atualmente e futuramente (WCDE, 1987, n.p.). Para tanto, entende-se como fundamental a busca pela harmonização entre as dimensões básicas do desenvolvimento sustentável, que são a econômica, a social e a ambiental (SACHS, 2007; VAN BELLEN, 2005), de maneira que seja possível a prática de diferentes papéis sociais por vários atores na sociedade.

Fez-se necessário, assim, que toda a sociedade se envolva em harmonizar as dimensões fundamentais do desenvolvimento sustentável de modo que se consiga usufruir os recursos naturais da melhor maneira possível para a continuidade tanto das gerações atuais como das futuras, no atendimento de suas necessidades. Tal fato é citado por Buarque (2008) como a solidariedade intra e intergeracional, respectivamente. Para tanto, na Agenda 21, documento resultante da Conferência das Nações Unidas sobre Meio Ambiente e Desenvolvimento (conhecida popularmente como Eco-92), estão dispostas ações que devem ser tomadas por diferentes atores sociais, dentre os quais podem ser identificados os governos, as empresas e os outros atores da sociedade atuantes em grupos ou de forma individual (CNUMAD, 1992).

\subsection{Adequação ao contexto e estudos já publicados: uma visão macro}

Em seu debate sobre o significado do constructo desenvolvimento sustentável, Fergus e Rowney (2005) fazem uma discussão em torno da origem e da essência que os conceitos que acompanham essa temática assumem no contexto social. Assim sendo, os autores trazem os seguintes questionamentos: "o desenvolvimento sustentável é uma epistemologia inclusiva fundada na ética e no valor real?" e "esta epistemologia, incorporada nas culturas, traz adicionais para as organizações ou se tornou um slogan usado na linguagem dos negócios, sem qualquer significado real?". Conforme os estudiosos, é preciso que haja uma mudança no paradigma científico-econômico como um todo, para que a melhor compreensão do desenvolvimento sustentável possa ser realizada.

Essa discussão é apresentada também por Lélé (1991), quando o autor indica, sob uma perspectiva crítica, as contradições existentes inerentemente à temática, bem como os debates que são realizados. Sem a consideração do conceito literal, ecológico e social, torna-se preocupante a discussão sobre desenvolvimento sustentável. Nas últimas décadas, o modelo de desenvolvimento capitalista tem buscado incorporar à sua dinâmica as discussões sobre o desenvolvimento sustentável, a partir da criação de mecanismos como o mercado de carbono, mencionado anteriormente. Baseado nessa noção, considera-se existente a crise capitalista, o que traz a fundamentação para a relevância da contribuição acadêmica.

Diversos artigos buscam identificar o que se estuda sobre desenvolvimento sustentável ou sustentabilidade (GALLON et al., 2007; JUNQUEIRA; MAIOR; PINHEIRO, 2011; MACHADO JR.; SOUZA; RIBEIRO, 2012; OLIVEIRA; MARTINS; LIMA, 2010; PEREIRA et al., 2011; SILVA et al., 2011; VARANDAS JR.; MIGUEL; CARVALHO, 2011; VELTER et al., 2010). A maioria desses trabalhos tem focado uma perspectiva bibliométrica, que apresenta como essência a identificação quantitativa de determinados aspectos em diferentes estudos, os quais podem envolver a quantidade de palavras e expressões de trabalhos, os principais autores e coautores, a quantidade de estudos de determinada temática etc. (ARAÚJO, 2006). 
No entanto, para o desenvolvimento desta pesquisa, optou-se por uma perspectiva crítica, uma vez que, de acordo com Junqueira, Maior e Pinheiro (2011), os balanços críticos contribuem para a compreensão de uma área do conhecimento, no caso, o desenvolvimento sustentável. De tal modo, busca-se considerar a profundidade e as fragilidades dos trabalhos publicados no evento selecionado, de acordo com a temática escolhida para estudo, sem que haja minimização das contribuições que foram originadas por cada trabalho em sua especificidade. Diante dessas argumentações, são apresentados a seguir os procedimentos metodológicos utilizados para o desenvolvimento da pesquisa.

\section{PROCEDIMENTOS METODOLÓGICOS}

Visando identificar como a temática do desenvolvimento sustentável vem sendo abordada em meio ao contexto atual de crise do capitalismo, a presente pesquisa foi realizada com caráter exploratório a partir de duas etapas distintas. Em um primeiro momento, houve o levantamento quantitativo dos trabalhos que poderiam ser considerados parte do universo de pesquisa. Em seguida, sob uma abordagem qualitativa, analisou-se o alinhamento dos conceitos apresentados na amostra selecionada com a essência do desenvolvimento sustentável. Assim sendo, a complementaridade entre os métodos de pesquisa fornece maior robustez para a compreensão do fenômeno estudado (CRESWELL, 2010).

Nesse contexto, considera-se que esta pesquisa tem inspiração bibliométrica na medida em que, segundo Araújo (2006), este estudo pode ser utilizado como indicador da produção científica de determinado assunto. A pesquisa não é classificada como bibliométrica, visto que, inicialmente, limitou-se a realizar um levantamento dos trabalhos publicados em determinado período, o que foi complementado por uma análise crítica dos trabalhos publicados acerca da temática do desenvolvimento sustentável. Com isso, pode-se identificar qual o posicionamento efetivo do atual discurso acadêmico sobre a temática.

A partir dessa noção, consideram-se, como universo da pesquisa, os trabalhos publicados em quatro anos no Encontro Nacional de Gestão Empresarial e Meio Ambiente (ENGEMA), evento específico para a temática da sustentabilidade. Foi identificado um total de 766 estudos publicados, sendo: em 2008, 167 artigos; em 2009, 129 artigos; em 2010, 255 artigos; e, em 2011, 215 artigos. No entanto, deve-se salientar que os artigos publicados nos Anais do ENGEMA de 2009 não foram verificados em sua totalidade, visto que os mesmos estão apresentados na web de forma aleatória, dificultando sua coleta pelos pesquisadores.

Com os artigos levantados, iniciou-se a identificação de quais possuíam algum direcionamento para a temática do desenvolvimento sustentável. Para tanto, foram analisados os títulos e os resumos de todos os trabalhos, utilizando como palavras-chave para a pesquisa os termos "Desenvolvimento Sustentável" e "Sustentabilidade". Assim, foram identificados 294 estudos como amostra de análise, sendo: em 2008, 65 artigos; em 2009, 48 artigos; em 2010, 87 artigos; e, em 2011, 94 artigos. A partir de tal levantamento, empregou-se uma perspectiva crítica para identificar quais seriam os artigos que, de fato, focam o desenvolvimento sustentável.

Em seguida, utilizaram-se filtros que facilitassem uma nova seleção dos artigos. Tal filtragem considera a profundidade da temática, a qual poderia ter: a essência da sustentabilidade, o foco em uma parte da temática, o foco organizacional ou, ainda, assumir técnicas e ações que trabalhem mais o "esverdeamento" do capitalismo do que a temática do desenvolvimento sustentável propriamente dita. Dessa maneira, a análise de conteúdo realizada focou os trabaIhos voltados para a essência da sustentabilidade, baseando-se na perspectiva teórica de Bardin 
(2009). Essa autora alega que é possível extrair dos dados analisados as principais contribuições para o tema de estudo e a temática selecionada. Ressalta-se que, para evitar interpretações errôneas, foca-se o valor relativo de cada categoria, o que facilita a comparação entre os anos.

\section{RESULTADOS E DISCUSSÕES}

Para o desenvolvimento das análises, optou-se por efetuar dois procedimentos. Inicialmente, considerando que foram analisados todos os trabalhos publicados em quatro anos no evento, realizou-se uma discussão sobre o que existe de produção nas diferentes áreas. Desse modo, percebe-se mais claramente o que os acadêmicos estão focando e como se posicionam no contexto atual. Posteriormente, como forma de atender ao objetivo de pesquisa proposto, realizou-se uma discussão sobre o modo como o desenvolvimento sustentável vem sendo abordado - a partir de uma reclassificação dos artigos que lidam com a temática. Com tal organização, foram, então, discutidos os discursos e as práticas sobre a temática.

\subsection{0 que existe de produção durante o período analisado?}

Para identificar o que se tem publicado no ENGEMA em meio ao período de crise do capitalismo, o Quadro 1 representa quais foram as principais discussões realizadas. Como se pode observar, os temas selecionados dão destaque às temáticas que mais aparecem nos trabalhos analisados. Vale ressaltar que, no ano de 2009, a categoria "Outros" abarca tanto os trabalhos sobre temáticas diversas como aqueles que foram apresentados em modalidade pôster - o que não foi considerado no momento das análises, visto que se torna difícil identificar o que os autores buscam transmitir em tão poucas palavras.

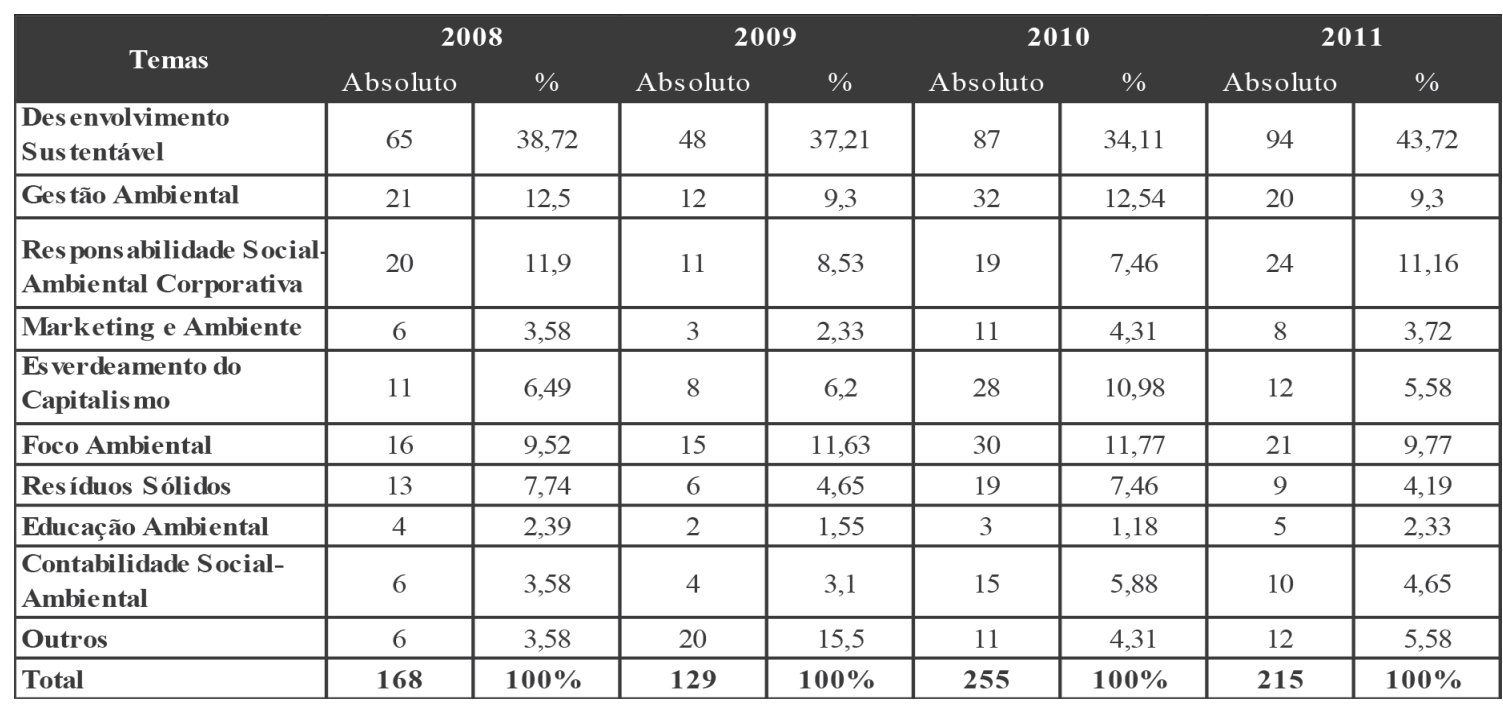

Quadro 1. Quantidade absoluta e em percentual dos resultados encontrados

Os dados apresentados no Quadro 1 demonstram de forma relativa (em \%) a existência de uma linearidade nas temáticas selecionadas para discussão. Como se percebe, pode-se dar destaque para o ano de 2010, pela maior concentração de artigos publicados, trazendo a oportunidade de que discussões diferentes fossem realizadas. Assim, como forma de melhor visualizar esses da- 
dos, apresenta-se, no Gráfico 1, o panorama de publicações ao longo dos anos analisados.

Observando o Gráfico 1, identifica-se maior direcionamento a estudos focados no desenvolvimento sustentável. Entretanto, em meio a esses trabalhos, estão artigos que vão desde ações operacionais e ideológicas desse modelo de desenvolvimento até discussões focadas na gestão organizacional. É esse segundo ponto que se busca evitar. Fergus e Rowney (2005) alegam que muito do que vem sendo discutido sobre a temática tem sido incorporado ao mundo dos negócios de forma equiparada à discussão macro sobre o tema. Apesar dessa visão, existem outras nomenclaturas que podem ser utilizadas nesse sentido, como responsabilidade social e ambiental, por exemplo. Falar de desenvolvimento sustentável é lidar com uma perspectiva social complexa que não se limita a um único contexto de sociedade. Logo, constata-se a discussão seguinte como pertinente.

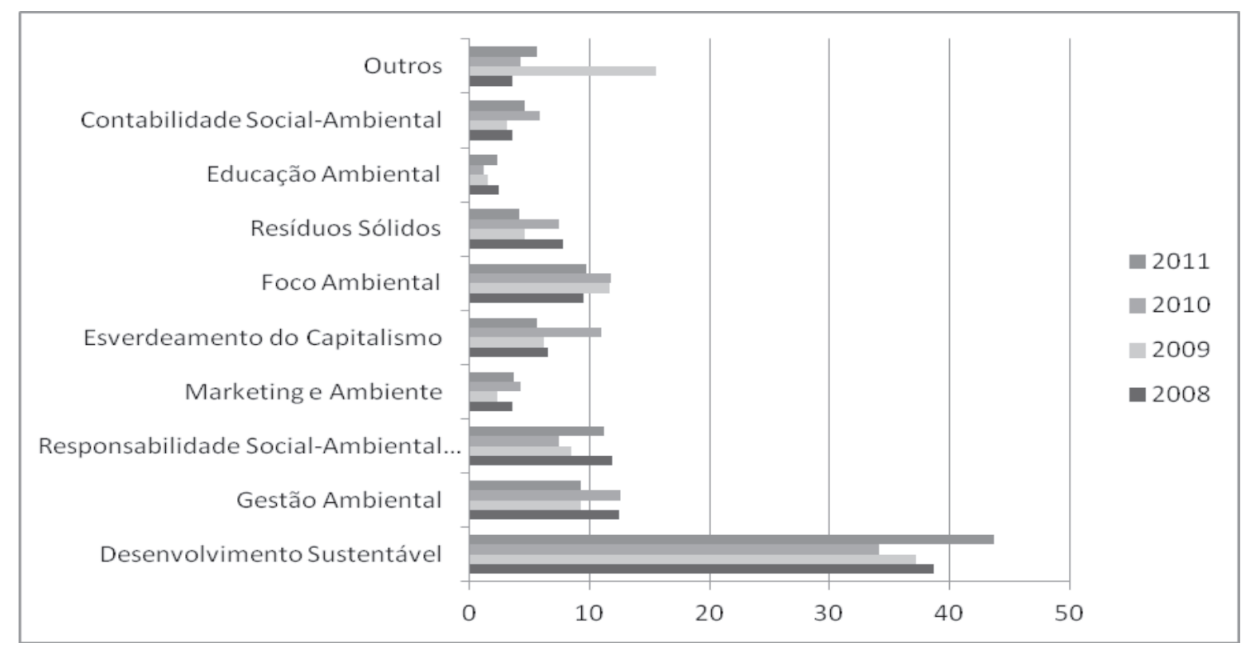

Gráfico 1. Evolução da produção acadêmica analisada

\subsection{Houve evolução sobre o tema desenvolvimento sustentável?}

Para considerar o discurso acadêmico sobre a temática selecionada, utiliza-se a visão de evolução do tema (RIBEIRO; CORRÊA, 2012). No Quadro 2 e no Gráfico 2, pode-se notar que a direção dada aos trabalhos sobre desenvolvimento sustentável ou sustentabilidade está no foco organizacional e na criação de técnicas e ações para o "esverdeamento" do capitalismo. Atualmente, o que se tem nas discussões acadêmicas é uma permanência do status quo (HOPWOOD; MELLOR; O'BRIEN, 2005), que não tem como ambição um novo posicionamento coletivo voltado para novos valores, mas busca soluções práticas para a incorporação de um novo tema ao mesmo paradigma econômico-científico (LÉLÉ, 1991). 


\begin{tabular}{|c|c|c|c|c|c|c|c|c|}
\hline \multirow[b]{2}{*}{ Desenvolvimento Sustentável } & \multicolumn{2}{|c|}{2008} & \multicolumn{2}{|c|}{2009} & \multicolumn{2}{|c|}{2010} & \multicolumn{2}{|c|}{2011} \\
\hline & Absoluto & $\%$ & Absoluto & $\%$ & Absoluto & $\%$ & Absoluto & $\%$ \\
\hline Es sência do tema & 20 & 30,77 & 8 & 16,67 & 10 & 11,49 & 15 & 15,96 \\
\hline $\begin{array}{l}\text { Análise por partes menores } \\
\text { (ex. dimensões) }\end{array}$ & 6 & 9,23 & 5 & 10,42 & 16 & 18,39 & 18 & 19,15 \\
\hline Foco organizacional & 28 & 43,08 & 14 & 29,16 & 29 & 33,33 & 35 & 37,23 \\
\hline $\begin{array}{l}\text { Técnicas e ações para } \\
\text { es verdeamento do capitalis mo }\end{array}$ & 11 & 16,92 & 21 & 43,75 & 32 & 36,79 & 26 & 27,66 \\
\hline Total & 65 & $100 \%$ & 48 & $100 \%$ & 87 & $100 \%$ & 94 & $100 \%$ \\
\hline
\end{tabular}

Quadro 2. Quantidade absoluta e em percentual dos artigos sobre desenvolvimento sustentável

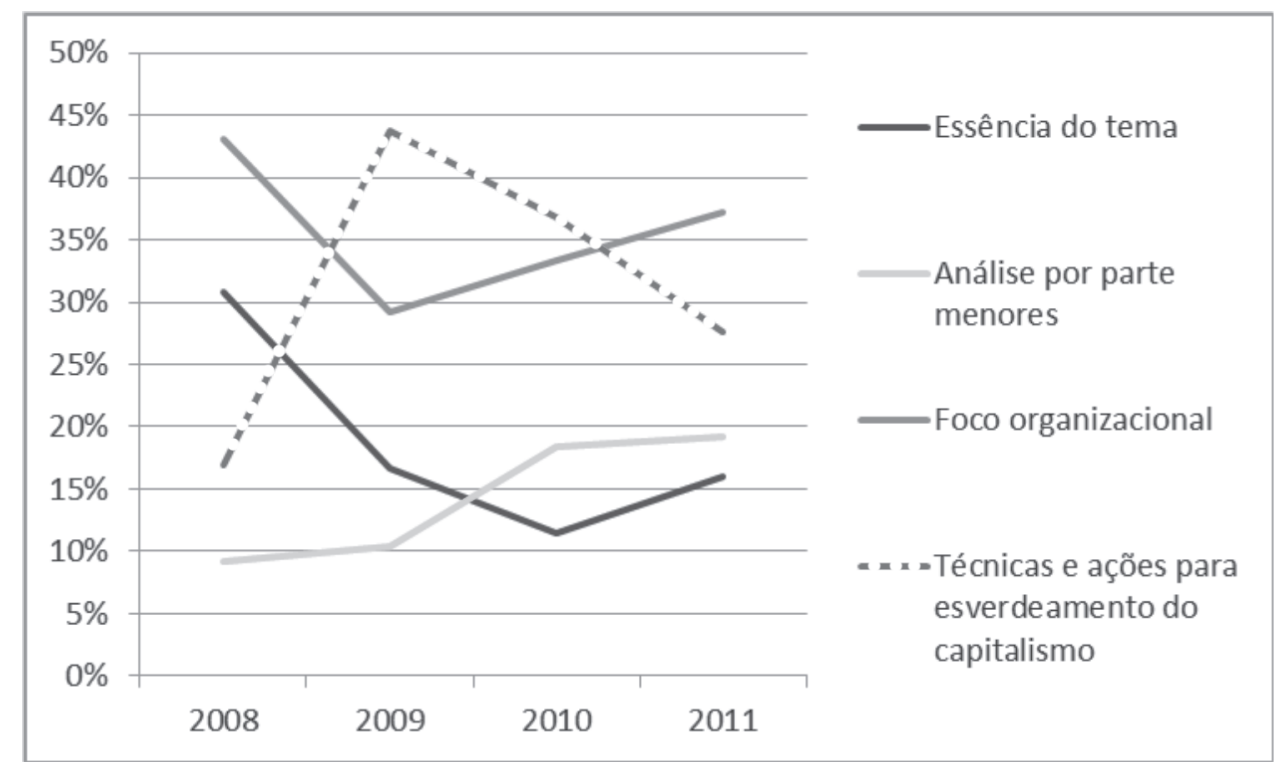

Gráfico 2. Evolução dos trabalhos do ENGEMA acerca de cada uma das temáticas.

Em relação aos dados e às considerações anteriormente realizadas, o ano de 2010 apresenta maior evidência. Ressalta-se que esse foi o ano com maior número de pesquisas com foco em técnicas para "esverdeamento" do capitalismo, especialmente no que diz respeito ao mercado de carbono, por exemplo, porque o foco e a temática do evento como um todo trouxeram à tona a discussão sobre esse tipo de mercado. Além disso, vale evidenciar a existência de trabaIhos que focam a análise de partes menores da temática, como o foco na dimensão ambiental e nas ações individuais. Tal perspectiva pode estar relacionada com uma visão mais coletivizada, mas a utilização do termo em si é equivocada.

Apesar dessa visão mais crítica, percebe-se que, em vários dos trabalhos que tratam da essência do desenvolvimento sustentável, há uma discussão sobre os pilares que norteiam sua existência enquanto discussão acadêmica focada em um modelo alternativo, bem como formas, mesmo que incipientes, de visões que incitam um novo posicionamento, mais operacional, dessa temática. De forma ampla, inicialmente, o que se observa é a disseminação do conceito apresentado pelo Relatório Brundtland, que traz a discussão sobre a utilização dos recursos com preocupação em atender às necessidades das gerações atuais e futuras, na busca por qualidade de vida e bem-estar social (WCDE, 1987). Tal pensamento é apresentado nos seguintes fragmentos selecionados dos artigos analisados: 
Desenvolvimento Sustentável como aquele que atende as necessidades do presente sem comprometer as possibilidades das gerações futuras de atenderem suas próprias necessidades.

[...] conceito que trata especificamente de uma nova maneira de a sociedade se relacionar com seu ambiente de forma a garantir a sua própria continuidade e a de seu meio externo.

Desenvolvimento Sustentável é um processo de transformação no qual a exploração dos recursos, a direção dos investimentos, a orientação do desenvolvimento tecnológico e a mudança institucional se harmonizam e reforça o potencial presente e futuro, a fim de atender às necessidades e aspirações futuras.

Esta formulação [do Relatório Brundtland], apesar de imprecisa e vaga, desencadeou muitas propostas de ação, provocando a adesão de um conjunto amplo de atores das mais variadas concepções ideológicas.

Mesmo não sendo esse conceito isento de críticas, este foi um importante passo dado no sentido de alertar o mundo da existência de problemas que devam ser solucionados deseja-se que as novas gerações consigam viver dignamente.

A partir disso, percebe-se que esse discurso está disseminado na academia e que não está atrelado apenas a uma ideologia - como se observa no terceiro fragmento citado, por exemplo, em que já há novas discussões que visam melhorar a operacionalização do desenvolvimento sustentável. Além dessa perspectiva mais real da temática, existem outras formas de discussão que envolvem a ideia de dimensões da sustentabilidade. Dentre os precursores dessa noção, Ignacy Sachs recebe destaque e menção nos trabalhos analisados, ao considerar a necessidade de diferentes contextos a serem analisados. Vale salientar a certa limitação dada ao pensamento de Sachs, visto que, para o autor, deve haver equilíbrio entre tais dimensões.

Em uma perspectiva pragmática, Silva, Costa e Gómez (2011) argumentam sobre a necessidade de harmonia entre essas dimensões, visto que consideraram utópica a utilização do jargão equilíbrio. Segundo os autores, "o equilíbrio é utópico, haja vista que somente poderia ser atribuída tal definição se houve uma compensação igualitária em relação às dimensões ambiental e social e os resultados obtidos na dimensão econômica" (SILVA; COSTA; GÓMEZ, 2011, p. 77). De certa forma, este parece ser o posicionamento dos acadêmicos acerca da temática: são céticos quanto ao equilíbrio, mas acreditam nas interações entre essas diferentes dimensões. Essa visão aparece nos seguintes trechos dos trabalhos analisados:

O conceito de desenvolvimento sustentável tem, é claro, limites - não limites absolutos, mas limitações impostas pelo estágio atual da tecnologia e da organização social, no tocante aos recursos ambientais, e pela capacidade da biosfera de absorver os efeitos da atividade humana.

[...] o desenvolvimento sustentável deve ser entendido como bem mais do que um novo paradigma de desenvolvimento, no qual a ideologia de uma sociedade equitativa, um ambiente equilibrado e uma economia eficiente são os aspectos que norteiam os princípios essenciais definidos.

Na busca por um novo modelo de desenvolvimento sustentável torna-se necessário o reconhecimento da diversidade dessa estrutura através das múltiplas dimensões da sustentabilidade e os objetivos distintos que orienta os modos de vida da sociedade.

Surge de uma relação harmônica do homem com a natureza, como centro de um processo de desenvolvimento que deve satisfazer às necessidades e aspirações humanas. [...] o conceito de desenvolvimento sustentável, tornando as questões ambientais e de desenvolvimento indissoluvelmente ligadas.

[...] como um desenvolvimento preocupado não somente com aspectos econômicos, mas também com as condições sociais particulares dos povos e com a capacidade de exploração dos recursos naturais. 
Por tratar de uma concepção de desenvolvimento multifacetada, envolvendo questões econômicas, ambientais, sociais, culturais e políticas, o esperado é o aumento das dificuldades, o que alimenta o ceticismo de muitos.

Um dos desafios da construção do desenvolvimento sustentável é o de criar instrumentos de mensuração que associem variáveis de diversas esferas, revelando significados mais amplos sobre os fenômenos aos quais se referem.

[...] [Surgem, assim,] metodologias capazes de gerar informações acerca dessa nova forma de desenvolvimento, são os chamados Sistemas de Indicadores de Sustentabilidade.

[...] embora o desenvolvimento sustentável venha sendo encarado como uma meta a ser alcançada por muitos governos nacionais, a tarefa de se medir a sustentabilidade têm se estendido também a uma cidade, a um setor ou a um negócio.

Desse modo, observa-se que o discurso está alinhado e preocupado com as condições que são apresentadas pelos contextos social e ambiental. Cabe advertir que os últimos fragmentos discorrem sobre indicadores e ferramentas de análise da sustentabilidade. Esta tem sido uma das principais preocupações acadêmicas atualmente: operacionalizar, mensurar e evidenciar quais são os impactos humanos no meio, procurando possíveis soluções e posicionamento por parte de toda a sociedade. Nesse sentido, é válido o estudo sobre indicadores de sustentabilidade organizacional, no entanto, sem buscar passar a ideia macro inerente à temática e às noções do desenvolvimento sustentável.

Além dessas discussões, há um debate mais profundo para alguns autores (FERGUS; ROWNEY, 2005; FOLADORI, 2005; HOPWOOD; MELLOR; O'BRIEN, 2005; dentre outros) que trazem a ideia de desenvolvimento sustentável voltada para uma perspectiva de mudança. Tal mudança não foca aspectos simples e fáceis de serem alcançados e está embasada em um contexto macro, considerando o sistema de desenvolvimento e os modos de produção e consumo como um todo. Acredita-se em uma mudança paradigmática, de uma visão econômico-científica para uma visão sustentável (LÉLÉ, 1991), em que o significado de sustentável é considerado a partir de uma perspectiva coletiva, na qual novas ações sociais e posicionamentos são trabalhados. Esse pensamento pode ser verificado nos fragmentos a seguir:

As concepções sobre desenvolvimento sustentável demandam mudanças profundas nas relações homem/natureza. Assim, há uma interessante emergência de novas abordagens, das quais algumas conflitam e outras aceitam co-existir, porém numa perspectiva de avanços e mudanças de visões e práticas.

[...] o processo de mudança do paradigma cartesiano para o paradigma da sustentabilidade "está em andamento e envolve todas as áreas do pensamento e da ação humana".

[...] paradigma de sustentabilidade emerge como aquele que deve partir da crítica do conhecimento existente, e evoluir do mono culturalismo ao multiculturalismo de tal forma que o domínio global da ciência moderna não possa silenciar os outros saberes, e assim, emancipe-se um conhecimento que consiga discernir a objetividade da neutralidade.

[...] as mudanças paradigmáticas que vão orientando as atividades humanas e a evolução do entendimento conceitual acerca do desenvolvimento sustentável são questões que estão imbricadas.

[...] mudança de paradigma quanto à natureza do relacionamento da sociedade com o meio ambiente.

[...] a proposta de uma nova perspectiva de se observar o mundo, visto que a visão atual revela um comportamento inadequado para se que se alcance o desenvolvimento sustentável, comprometendo as gerações futuras. 
Então, averígua-se que existem autores que percebem a necessidade da mudança. Todavia, esse deveria ser um pensamento mais disseminado para todos aqueles que, de fato, realizam pesquisas dentro da temática. Não se quer com isso indicar que as discussões realizadas sejam dispensáveis ou desnecessárias, mas que estas necessitam aprofundar a temática nas suas propostas. No atual contexto, é clara a dificuldade de lidar com essa visão ideológica em um primeiro momento, até porque as pressões externas e mercantilizadas (mesmo na academia) criam barreiras para isso. No entanto, o processo de mudança deve ocorrer em uma fase de crise, criando maior embasamento dessa proposta e levando em consideração as variações existentes no modelo apregoado. Salienta-se que esse é um processo lento, mas que deve ser contínuo e profundo em sua finalidade.

O que se verifica na quase totalidade dos artigos é o processo de construção teórica ao qual o tema está submetido, faltando aprofundamento teórico em alguns sentidos. Nessa perspectiva, notoriamente, existem artigos que evidenciam a sustentabilidade como um aspecto de continuidade de ações e práticas no meio, focando um contexto de sustentação, o que distorce a ideia essencial da temática. Isso foi verificado, especialmente, em um dos artigos analisados, que discute a questão do autossustentar de aspectos que norteiem as ações de determinada localidade. Para que essa mudança seja possível, um dos caminhos identificados é a mudança no contexto educacional de toda a sociedade.

Nesse sentido, os pesquisadores voltados para uma perspectiva de mudança mais profunda preocupam-se com uma educação para a sustentabilidade, principalmente no campo da Administração, que seria base para a efetivação dos conceitos nas ações e práticas do cotidiano da sociedade e nas organizações. Tal fato pode ser explicado uma vez que o campo de estudo é o da gestão, mas existem movimentos em diversos campos do conhecimento voltados para a inserção de aspectos da sustentabilidade em diferentes níveis da formação educacional. No que se refere ao pensamento no campo da Administração, os seguintes fragmentos começam a representar o que os autores têm escrito sobre a temática:

A formação de administradores com pressupostos orientados pela sustentabilidade exige novas propostas pedagógicas interdisciplinares em que a visão integrada, sistêmica, holística substitua os projetos pedagógicos disciplinas que privilegiam o processo de compreensão do aluno sobre sua realidade de forma fragmentada.

[...] a ideia aqui proposta de sustentabilidade implica na premissa de que é preciso definir limites às possibilidades de crescimento de determinada sociedade, delineando um conjunto de iniciativas que levem em conta a existência de interlocutores e participantes sociais relevantes e ativos, reforçando a corresponsabilidade e a constituição de valores éticos.

Como é possível notar, são transformações no processo educacional que tratam de novos valores e comportamentos, mais éticos e preocupados com o impacto em toda a sociedade. Este é outro ponto que se apresenta complexidade: as mudanças propostas são muito profundas. Criando uma analogia com a proposta de mudança apresentada por Marx, é necessária a produção de consciência coletiva, uma mudança em diferentes níveis, com vários caminhos. Até então, pode-se perceber que está ocorrendo maior direcionamento de pesquisas voltadas para a preocupação com o impacto do homem no ambiente, o que é tido como o ponto inicial para a mudança. Deve-se, entretanto, buscar uma mudança que gere um novo posicionamento de diferentes atores na sociedade, a fim de que haja harmonia entre diferentes dimensões, mudanças profundas e preocupação com o atendimento das necessidades das gerações atuais e futuras. 


\section{IMPLICAÇÕES ACADÊMICAS}

A sociedade como um todo tem passado por mudanças em diferentes contextos, as quais influenciam os comportamento dos indivíduos, das empresas e, como não mencionar, dos acadêmicos e pensadores do contexto social. Muitos se mostram céticos com as mudanças, outros otimistas com o que pode vir - porém, o que pode vir? Não existem respostas definidas, mas discussões. $O$ que se sabe de fato é que o capitalismo não terá uma mudança radical imediata; no entanto, as discussões podem começar a considerar a possibilidade de mudança para um novo modelo de desenvolvimento e de negócios. Além disso, pode-se afirmar que o paradigma atual vive em profunda crise e que a sustentabilidade se definirá como seu sucessor, capaz de resolver o complexo dilema entre as dimensões da sociedade (CARREIRA, 2011).

Apesar dessa noção, pode-se discutir na academia questões mais essenciais. Seria o termo desenvolvimento sustentável o mais correto a ser utilizado? De forma segmentada e aproximada, os termos desenvolvimento e sustentável individualmente trazem preconceitos e significados que podem confundir aqueles que discutem a temática. Essa mesma inquietação aparece nos trabalhos de Lélé (1991), Fergus e Rowney (2005), Foladori (2005), Barbieri et al. (2010), dentre outros, que mostram o quão difícil e necessária é a discussão sobre a temática. Nesse caso, constata-se que o posicionamento acadêmico precisa se tornar mais crítico quanto ao que é discutido, visto que os embasamentos e as deliberações sobre a temática ainda não possuem uma clara consolidação.

Dessa maneira, espaços massificados para a discussão devem ser mais bem utilizados e explorados por aqueles que discutem a temática. Isso se torna possível com processos de maior participação coletiva e envolvimento social. Em 2012, ocorreu a Conferência Rio+20; o que se constatou, todavia, no evento, foi a concentração de decisões na mão de poucos, sem considerar, por exemplo, as discussões paralelas realizadas na Cúpula dos Povos. São questões como essa que devem ser mais profundamente observadas. Quanto aos eventos acadêmicos, tem ocorrido uma tendência em inserir a temática nas discussões, o que se mostra um avanço em relação ao que acontecia até então, e isso deve ser considerado por toda a comunidade acadêmica como positivo e favorável a um novo direcionamento dos trabalhos realizados.

Em sentido contrário a essa tendência, a decisão de criar um evento totalmente voltado para a temática, o Encontro Nacional de Gestão Empresarial e Meio Ambiente (ENGEMA), já surgiu como um marco para os estudos realizados no Brasil. Foi uma iniciativa que merece menção e destaque como aspecto que contribui para as evoluções nacionais sobre a temática. Entretanto, como informa o próprio nome do evento, seu foco está voltado para o posicionamento empresarial acerca dessa temática. Sabe-se que as empresas têm papel de extrema importância na sociedade; todavia, estão imersas em um paradigma tecnológico e econômico de lucro extraordinário a todo custo e, em sua maioria, não conseguem melhor se posicionar nas discussões sobre a temática.

Existem muitos exemplos de empresas que estão assumindo novas posições e ações no mercado, o que é observado na incorporação de uma visão estratégica sobre a temática. Porém, tais empresas ainda recebem muitas desconfianças sobre suas motivações e pretensões em prol da sustentabilidade. Alguns alegam ser impossível o fato de as empresas se posicionarem nesse sentido; outros acreditam que há essa possibilidade. O que não deve haver nas discussões sobre a temática é espaço para uma teoria da conspiração, na qual todas as intenções são desfavoráveis e todos estão atuando apenas sob uma perspectiva calculista de suas ações. Para que a mudança possa ocorrer, é preciso que haja compromisso e responsabilidade compartilhada por todos os atores da sociedade, em busca de uma mudança coletiva.

Dessa maneira, as temáticas no campo da Administração devem continuar direcionadas 
à mudança, mas gradualmente devem direcionar-se para esse novo modelo de desenvolvimento. A utilização de técnicas e iniciativas para esverdear o capitalismo (como o mercado de carbono, a produção mais limpa e outras ações) deve ser substituída pela preocupação com a redução de emissão do $\mathrm{CO} 2$ (ao invés de querer mercantilizá-lo), bem como por novas práticas de produção que não precisem dessa "limpeza" em sua operacionalização. Com isso, novas discussões serão realizadas e novos comportamentos poderão ser incorporados. De tal modo, acredita-se que a área desse campo que possivelmente mais necessite dessas discussões é a de Teorias Organizacionais, uma vez que lida com processos de interações organizações-sociedade.

\section{CONSIDERAÇÕES FINAIS}

A discussão sobre crise do capitalismo tem trazido muitas inquietações em diferentes instâncias em todo o planeta. São muitos os atores e aqueles que se posicionam a favor de mudanças ou de encontrar bases e estímulos para a continuidade do sistema. No contexto acadêmico brasileiro, identificou-se uma tendência a buscar adequar as questões socioambientais para a manutenção do capitalismo. Entretanto, em alguns casos, foram verificadas pesquisas que realizam suas discussões de maneira mais profunda e efetuam questionamentos mais claramente. Salienta-se que essa visão não está errada, mas que os avanços atuais estão focados mais no "esverdeamento" do capitalismo do que na evolução de discussões que privilegiem a perspectiva de mudança e reestruturação do sistema.

Diante das discussões realizadas, percebe-se que este artigo atendeu ao seu objetivo de analisar criticamente os trabalhos publicados em um evento com foco em questões sustentáveis, observando de fato o panorama existente sobre a temática. Dessa maneira, percebe-se que não necessariamente se está "chovendo no molhado" nas discussões acadêmicas; no entanto, elas estão desvirtuadas da possibilidade de contribuição, mesmo que ideológica e paradigmática, de um pensamento alternativo às pressões e implicações sobre o meio. Assim, elas se mostram pouco suficientes para se falar em uma mudança mais estrutural.

Apesar dessa noção, a tendência tem sido modificada para o entender dessa questão de forma mais profunda. O trajeto ainda é longo, mas já iniciou. Os maiores pensadores do mundo estão se voltando para discussões mais profundas. O evento Academy of Management, realizado nos Estados Unidos, é considerado aquele que normatiza o que se estuda no campo da Administração, e sua edição de 2013 teve como temática o questionamento do capitalismo. Ora, se até mesmo aqueles que fazem parte do mainstream acadêmico estão considerando e questionando o atual sistema de produção, mesmo sem se conhecer até que ponto isso é fidedigno, será que um aprofundamento sobre o desenvolvimento sustentável, como uma visão alternativa, não será realizado?

Portanto, deve-se buscar uma visão mais qualificada do que a atual sobre o mundo almejado. Conforme foi citado no começo desta discussão, deve-se priorizar "ter melhor" e "usufruir" do que, de fato, impactar inconsequentemente o meio e as demais comunidades como um todo. Nota-se que a sociedade está no caminho, mas ainda existe uma árdua trajetória pela frente para que se possa focar uma mudança do paradigma. Se as discussões irão "chover no moIhado" ou irão construir um novo caminho, isso depende da possibilidade de real entendimento ao longo de todo o trajeto. Com isso, no momento em que surgem os raios do sol e essa chuva se torna fraca, na construção dessa nova visão, no fim do arco-íris que se cria, é possível que se encontre o pote de ouro, no qual todos os desejos ali se encontram.

Nessa perspectiva, assume-se que o limite para a realização desta pesquisa teve como foco o estudo do desenvolvimento sustentável em essência de sua intenção como valor social, 
procurando ter cuidado com os desdobramentos e as abduções que foram realizadas pelo atual modelo de desenvolvimento. Logo, toma-se como limitação deste estudo e das análises realizadas o viés dos pesquisadores na realização de suas análises, o que pode estar alinhado aos seus pressupostos ontológicos e perspectivas epistemológicas quanto ao entendimento da temática. De tal modo, propõe-se uma evolução sobre essas discussões à medida que trabalhos futuros consigam observar nuances, aqui não identificadas, e a realização de novas pesquisas críticas sobre outros temas que podem estar contribuindo com a mudança almejada.

\section{REFERÊNCIAS}

ARAÚJO, C. A. Bibliometria: evolução histórica e questões atuais. Em questão, v.12, n.1, p.1133. 2006.

BARBIERI, J. C.; VASCONCELOS, I. F. G.; ANDREASSI, T.; VASCONCELOS, F. C. Inovação e Sustentabilidade: Novos modelos e proposições. Revista de Administração de Empresas - RAE. V. 50, n.2, p.146-154. 2010.

BARDIN, L. Análise de Conteúdo. 4a ed. Lisboa: Edições 70, 2009.

BÖHM, S.; MISOCZKY, M. C.; MOOG, S. Decarbonizing by Sub-imperialism: A Marxist Critique of Climate Capitalism and Carbon Markets. Organization Studies. 2012.

BROWN, L. Eco-economia. EPI - Earth Policy Institute / UMA - Universidade Livre da Mata Atlântica. 2003. Disponível em: <http://www. ethos.org.br/_Uniethos/Documents/livro. pdf>. Acesso em: abr. 2012.

BUARQUE, S. C. Construindo o desenvolvimento local sustentável. 4a. Ed. Rio de Janeiro: Garamond, 2008.

CANEPA, C. Cidades sustentáveis: o município como lócus da sustentabilidade. São Paulo: RCS Editora, 2007.

CLARO, P. B. O.; CLARO, D. P.; AMÂNCIO, R. Entendendo o conceito de sustentabilidade nas organizações. Revista de Administração (FEA -USP), v.43, n.4, p.289-300, 2008.

CNUMAD - Conferência das Nações Unidas sobre Meio Ambiente e Desenvolvimento.
Agenda 21 Global. 1992. Disponível em: $<$ http://www.mma.gov.br/sitio/index.php?ido=conteudo.monta\&idEstrutura $=18 \&$ idConteudo=575\&idMenu=9065 >. Acesso em: jul. 2012.

CRESWELL, J. W. Projeto de pesquisa: métodos qualitativo, quantitativo e misto. 3 a ed. Porto Alegre: Artmed/Bookman, 2010.

DE COCK, C.; BAKER, M.; VOLKMANN, C. Financial fantasmagoria: corporate image-work in times of crisis. Organization, v.18, n.2, p.153172, 2011.

EAGLETON, T. Marx. São Paulo: Ed. UNESP, 1997.

In Praise of Marx. 2011. Disponível em: http://chronicle.com/article/In-Praise-of -Marx/127027/ Acesso em: mai. 2012.

ELKINGTON, J. Canibais com garfo e faca. São Paulo: Makroon Books, 2001.

FERGUS, A. H. T.; ROWNEY, J. I. A. Sustainable Development: Lost: Meaning and Opportunity? Journal of Business Ethics, v.60, p.17-27. 2005.

FOLADORI, G. Por uma sustentabilidad alternativa. Uruguai: Colección Cabichui, 2005.

FOSTER, J. B.; MAGDOFF, F. The great financial crisis - three years on. Monthly Review. 2011.

GALLON, A. V.; SOUZA, F. C.; ROVER, S.; VAN BELLEN, H. M. Produção científica e perspectivas teóricas da área ambiental: Um levantamento a partir de artigos publicados em congressos e periódicos nacionais da área de contabilidade e administração. In Anais... Congresso USP de Controladoria e Contabilidade. 
São Paulo: USP, 2007.

HOPWOOD, B.; MELLOR, M.; O'BRIEN, G. SUStainable Development: Mapping Different Approaches. Sustainable Development, n.13, 2005.

HAWKEN, P.; LOVINS, A. e LOVINS, H. Natural Capitalism: creating the next industrial revolution. Little Brown - USA, 1999. Disponível em: $<$ http://www.natcap.org/>. Acesso em: jul. 2012.

JUNQUEIRA, L. A. P.; MAIOR, J. S.; PINHEIRO, F. P. Sustentabilidade: A produção científica brasileira entre os anos de 2000 e 2009. Revista de Gestão Social e Ambiental - RGSA, v.5, n.3, 2011.

LÉLÉ, S. M. Sustainable Development" A Critical Review. World Development, v.19, n.6, p. 607-621, 1991.

MACHADO JR., C.; SOUZA, M. T. S.; RIBEIRO, H. C. M. A contribuição dos 15 anos do SIMPOI ao estudo as sustentabilidade ambiental: Um estudo bibliométrico. In Anais... XV Simpósio de Administração da Produção, Logísticas e Operações Internacionais - SIMPOI. São Paulo: FGV, 2012.

MANDEL, E. O lugar do marxismo na história. São Paulo: Xamã, 2001.

MARX, K. Existência e consciência. In: IANNI, Octavio (Org.) Sociologia, p.145-180. São Paulo: Câmara Brasileira do Livro, 1980.

NASCIMENTO, E. P. Trajetória da sustentabilidade: do ambiental ao social, do social ao econômico. Revista de Estudos Avançados. V. 26, n.74. 2012.

NORTON, B. G. Ethics and sustainable development: an adaptive approach to environmental choice. In: ATKINSON, G.; DIETZ, S.; NEUMAYER, E. (editors). Handbook of Sustainable Development. Edward Elgar Publishing, 2007.

OLIVEIRA, L. R.; MARTINS, E. F.; LIMA, G. B. A.
Evolução do conceito de sustentabilidade: Um ensaio bibliométrico. Relatórios de Pesquisa em Engenharia da Produção. V. 10, n.4. 2010.

ONARAN, Ö. The crisis of capitalism in Europe, West and East. Monthly Review. 2010.

PEREIRA, G. M. C.; YEN-TSANG, C.; MANZINI, R. B.; ALMEIDA, N. V. Sustentabilidade Socioambiental: Um estudo bibliométrico da evolução do conceito na área de gestão de operações. Produção. 2011.

PROTHERO, A.; FITCHETT, J. A. Greening Capitalism: opportunities for a green commodity. Journal of Macromarketing. V. 20. 2000.

RIBEIRO, H. C. M.; CORRÊA, R. Marketing Verde: Uma análise bibliométrica e sociométrica dos últimos 20 anos. In Anais... XV Simpósio de Administração da Produção, Logísticas e Operações Internacionais - SIMPOI. São Paulo: FGV, 2012.

SACHS, I. Rumo à ecossocioeconomia: Teoria e prática do desenvolvimento. São Paulo: Cortez, 2007.

\section{Caminhos para o desenvolvimento} sustentável. Rio de Janeiro: Garamond, 2008.

SILVA, M. E.; COSTA, A. C. V.; GÓMEZ, C. R. P. Sustentabilidade no Terceiro Setor: $O$ desafio de harmonizar as dimensões da sustentabilidade em uma ONG. Revista Reuna (Belo Horizonte). V.16, n.3., p. 75-92. 2011.

SILVA, M. Z.; DANI, A. C.; BEUREN, I. M.; KLOEPPEL, N. R. Características bibliométricas e sociométricas de publicações da área ambiental em congressos e periódicos nacionais. In Anais... XIII Encontro Nacional de Gestão Empresarial e Meio Ambiente - ENGEMA. São Paulo: FGV, 2011.

SMITH, N. Nature as accumulation strategy. Socialist Register, v. 43, 2007.

VAN BELLEN, H. M. Indicadores de Sustentabilidade: Uma análise comparativa. Rio de Janei- 
ro: Editora FGV, 2005.

VANDEPITTE, M. Crisis del capitalismo. 2011. Rebelión. Disponível em: <http://www.rebelion.org/noticia.php?id=121086>. Acesso em: mai. 2012.

VARANDAS JR., A.; MIGUEL, P. A. C.; CARVALHO, M. M. Análise bibliométrica da literatura sobre os conceitos de Product Life Cycle Management, Product Development Process e Sustentabilidade e suas interfaces. In Anais... III International Workshop Advances in Cleaner Production. São Paulo. 2011.

VEIGA, J. E. Sustentabilidade: a legitimação de um novo valor. São Paulo: Senac, 2010.

VELTER, A. L.; BATTISTELLA, L. F.; GROHMANN, M. Z.; CARPES, A. M. O estudo da sustentabilidade na Administração: Um levantamento dos "hot topics" publicados na última década. In Anais... XIII Seminários de Administração SemeAd. São Paulo: USP, 2010.

WCED - World Commission on Environment and Development. Report Our Common Future. Genebra, 1987. Disponível em: <http:// www.un-documents.net/wced-ocf.htm.>. Acesso em: jan. 2012. 